Original research article

\title{
Plasma disc decompression compared to physiotherapy for symptomatic contained lumbar disc herniation: A prospective randomized controlled trial
}

\author{
Mehdi Nikoobakht ${ }^{a}$, Mir Saeed Yekanineajd ${ }^{b}$, Amir H. Pakpour ${ }^{c, d, *}$, \\ Peter C. Gerszten ${ }^{e}$, Richard Kasch ${ }^{f}$ \\ ${ }^{a}$ Department of Neurosurgery, Iran University of Medical Sciences, Tehran, Islamic Republic of Iran \\ ${ }^{\mathrm{b}}$ Department of Epidemiology and Biostatistics, School of Public Health, Tehran University of Medical Sciences, \\ Tehran, Islamic Republic of Iran \\ ' Social Determinants of Health Research Center, Qazvin University of Medical Sciences, Shahid Bahounar BLV, \\ 3419759811, Qazvin, Islamic Republic of Iran \\ d Department of Public Health, Qazvin University of Medical Sciences, Qazvin, Islamic Republic of Iran \\ e Department of Neurological Surgery, University of Pittsburgh Medical Center, Pittsburgh, PA, USA \\ ${ }^{\mathrm{f}}$ Clinic and Outpatient Clinic for Orthopedics and Orthopedic Surgery, University Medicine Greifswald, Greifswald, \\ Germany
}

\section{A R T I C L E I N F O}

Article history:

Received 17 July 2015

Accepted 2 November 2015

Available online 28 November 2015

\section{Keywords:}

Contained disc herniation

Disc decompression

Low-back pain

Minimally invasive spine surgery

Plasma disc decompression

\begin{abstract}
A B S T R A C T
Introduction: To evaluate clinical outcomes with PDD as compared with patients who underwent to standard physiotherapy intervention.

Material and methods: One-hundred-seventy-seven randomly assigned patients with primarily radicular pain associated with a single-level lumbar contained disc herniation were enrolled. Participants received either PDD (89 patients) or conservative physiotherapy care (88 patients).

Results: Patients in the PDD group had significantly greater reduction in leg pain scores and significantly improved VAS $(p<0.001)$, Oswestry Disability Index $(p<0.05)$, and 36-Item Short Form, than those in the physiotherapy group at 12 months. On subset analysis, patients achieved even better outcomes after PPD who: were younger, had a shorter period of radiculopathy, of male gender, and lower BMI. Patients with subacute pain reported better outcomes than those with chronic pain in the PDD group.

Conclusions: Patient selection for PDD over physiotherapy favored younger patients who presented with a shorter period of pain symptoms and who had a more favorable body habitus.
\end{abstract}

(C) 2015 Polish Neurological Society. Published by Elsevier Sp. z o.o. All rights reserved.

\footnotetext{
* Corresponding author at: Social Determinants of Health Research Center, Qazvin University of Medical Sciences, Shahid Bahounar BLV, 3419759811 Qazvin, Islamic Republic of Iran. Tel.: +98 2833239259; fax: +98 2833239259.

E-mail addresses: Pakpour_Amir@yahoo.com, apakpour@qums.ac.ir (A.H. Pakpour). http://dx.doi.org/10.1016/j.pjnns.2015.11.001 0028-3843/@ 2015 Polish Neurological Society. Published by Elsevier Sp. z o.o. All rights reserved.
} 


\section{Introduction}

Low back pain is the world's number one cause of disability and one of the most prevalent health conditions [1]. Most patients also report radicular syndromes [2]. International guidelines provide recommendations on effective treatments for low back pain, starting with conservative or non-surgical treatment [3]. However, a considerable proportion of patients with lumbar disc herniations remain symptomatic even after undergoing conservative treatments. Epidemiological studies have shown that the rate of persistent sciatica is $1.6 \%$ in a given population [4] while this rate increases to $25 \%$ with aging up to 64 years [5].

For patients who respond poorly to conservative treatment, surgical treatment may be considered [6]. The optimal timing for surgical intervention is not known [7]. Over the past decade, much effort has been made for minimization in spinal surgery $[8,9]$. To this end, a minimally invasive technique has been developed to decrease intradiscal pressure through a percutaneously inserted device placed directly into the intervertebral discs. Several observational studies [9-12] have been performed to assess the safety and clinical outcome of the PDD procedure in the lumbar spine for radiculopathy [13]. One prospective, randomized, controlled lumbar was identified [13]. The use of PDD technology to treat lumbar radiculopathy due to a contained disc herniation is not well supported currently by high-level evidence [10-12,14]. Prospective randomized clinical trials with are required to confirm efficacy $[10,11]$. The aim of this prospective randomized controlled clinical investigation was to compare the clinical outcomes of patients with symptomatic lumbar disc herniation who were treated using either conservative therapy or the PDD procedure. A secondary goal was to better understand the appropriate patient for this procedure.

\section{Materials and methods}

The study was designed as a prospective single-blinded randomized controlled trial and was performed between November 2010 and March 2012. It included 177 patients with lumbosacral radicular syndrome in two groups, 89 patients who underwent percutaneous disc decompression using the PDD technique and 88 patients who underwent conservative treatment.

\subsection{Study protocol}

This trial was approved by the local Ethical Review Committee (No. B38). The protocol was registered with the university committee Trials Registry, number (IUMS-B39). Necessary precautions to protect the privacy of patients participating in this study were considered. The study was carried out according to the principles of the declaration of Helsinki.

\subsection{Patients}

All patients were selected consecutively from the University Hospital of Qazvin (Shahid Rajaee Hospital, Qazvin). Eligible patients included the following: age between 18 and 70 years, had normal neurological function, diagnosis of lumbosacral radicular syndrome by an attending neurologist (MN) (a chief complaint of leg pain, a positive straight leg raising (SLR) at less than 60 degrees reproducing the leg pain, radicular pain score of 50 or greater as measured using a 0 - to $100-\mathrm{mm}$ VAS; and had an ipsilateral MRI confirmed disc herniation), contained disc herniation $<6 \mathrm{~mm}$, with a disc height $>50 \%$ [15]. All patients who underwent percutaneous disc decompression using PDD or conservative treatment must previously have first conservative treatment for the same symptoms for at least 6 weeks up to 6 months. Patients may have experienced partial pain relief with residual symptoms, temporal pain relief or no response to the previously conservative treatment to be included in this trail.

Patients were excluded from the study for the following reasons: patients with more severe axial (back) pain than radicular (leg) pain, sciatica emerging from more than one disc level, clinical evidence of cauda eqina syndrome, severe neurological deficits, history of previously operated segments at or directly adjacent to the level to be treated, radiological evidence of spinal stenosis or spondylolisthesis at the level to be treated, acute osteomyelitis, spinal tumors, suspected or planned pregnancy within the study time period, uncontrolled psychological disorders, and ongoing treatment for drug or alcohol abuse. All patients with low back pain who were eligible to be included in the study were offered participation. Confirming patient eligibility was performed by three independent GPs (i.e. independent researchers). The GPs (as outcome assessors) were blinded to the randomization.

\subsection{Procedures}

A statistician not involved in data collection or analysis developed a randomization schedule and produced 177 consecutively numbered sealed opaque envelopes containing each participant's allocation. Randomization was performed using a computer-generated random allocations sequence.

The eligible patients who gave their consent were asked to participate in a session. During this session, the nature of this study was explained to all subjects along with an opportunity to ask questions and decide whether or not they wanted to participate. Informed consent was obtained from all patients who agreed to participate. All patients were asked not to tell the outcome assessors which intervention they received and the outcome assessors were also advised to remind the participants not to give them this information.

Patients were followed at baseline, 1 month, 3 months and 12 months after enrollment. Immediately after collecting baseline data by the same initial GP the allocation envelope was opened by a blinded researcher who guides the patients into one of the two groups. 177 patients were randomly assigned into PDD group ( $n=89$ ) and conservative group $(n=88)$.

\subsection{Intervention}

The percutaneous disc decompression procedure was performed by a single neurosurgeon (MN) under sterile conditions in the lateral position from the side of predominant pain using fluoroscopic guidance under moderate sedation, following the manufacturer's instructions. Daily activity after PDD was 
restricted in the following way: for the first 3 days sitting and walking was limited to up to $10-20 \mathrm{~min}$ at a time. No driving was allowed for the first 2 days, and lifting was limited to 3-4 kg during the first 2 weeks.

The control group was comprised of patients who were treated with conservative treatment alone. Conservative treatment was aimed mainly to reduce pain and consisted of the following activities: bed rest, active physical therapy, education and counseling with home exercise instruction, spinal manipulation, narcotic analgesics, muscle relaxants, analgesics, and nonsteroidal anti-inflammatory local injections. Physiotherapy was administered by seven experienced physiotherapists at 5 private clinics and consisted of 20 sessions per patient over the course of 12 weeks. The physiotherapy stopped if the patients recovered before estimated session. Following best clinical practice, the physiotherapy treatments were diverse from patients to other patients as each patient received a physiotherapy treatment which was appropriate for the individual clinical presentations. All physiotherapists had Master of Physical Therapy (MPT) and had worked frequently on patients with low back pain and spinal disorders in their private clinics. This non-operative treatment is considered as usual care for patients with lumbar disc herniation [16].

All patients received a reminder call and diary cards on which to record any side-effects during the follow-up assessments. Patients in both treatment groups were allowed to receive additional narcotic analgesics, or NSAIDs, at the discretion of the treating GP, who recorded the medication in the patients' records. An independent researcher who was not involved into treatment study analysis and data collection monitored the conservative treatment sessions to ensure that all patients adhere to the treatment.

\subsection{Study measures}

The primary outcomes of the study were changes in disability index and pain while the secondary outcome was changes in quality of life at baseline, 1 month, 3 months and 12 months after initial enrollment.

A self-reported questionnaire was used to collect sociodemographic variables including age, gender, work status and current smoking status. Furthermore, herniation level, duration of radicular pain, the previously treatment and BMI were taken from patients' records.

\subsubsection{Oswestry Disability Index (ODI), The Short Form-36,} Short Form McGill Pain Questionnaire (SF-MPQ)

An Iranian version of the ODI, SF-36, SF-MPQ were tested on patients with chronic LBP. The results indicated that the ODI, SF-36 and SF-MPQ are a reliable and valid instrument to measure functional status in Persian-speaking patients with LBP [16-18].

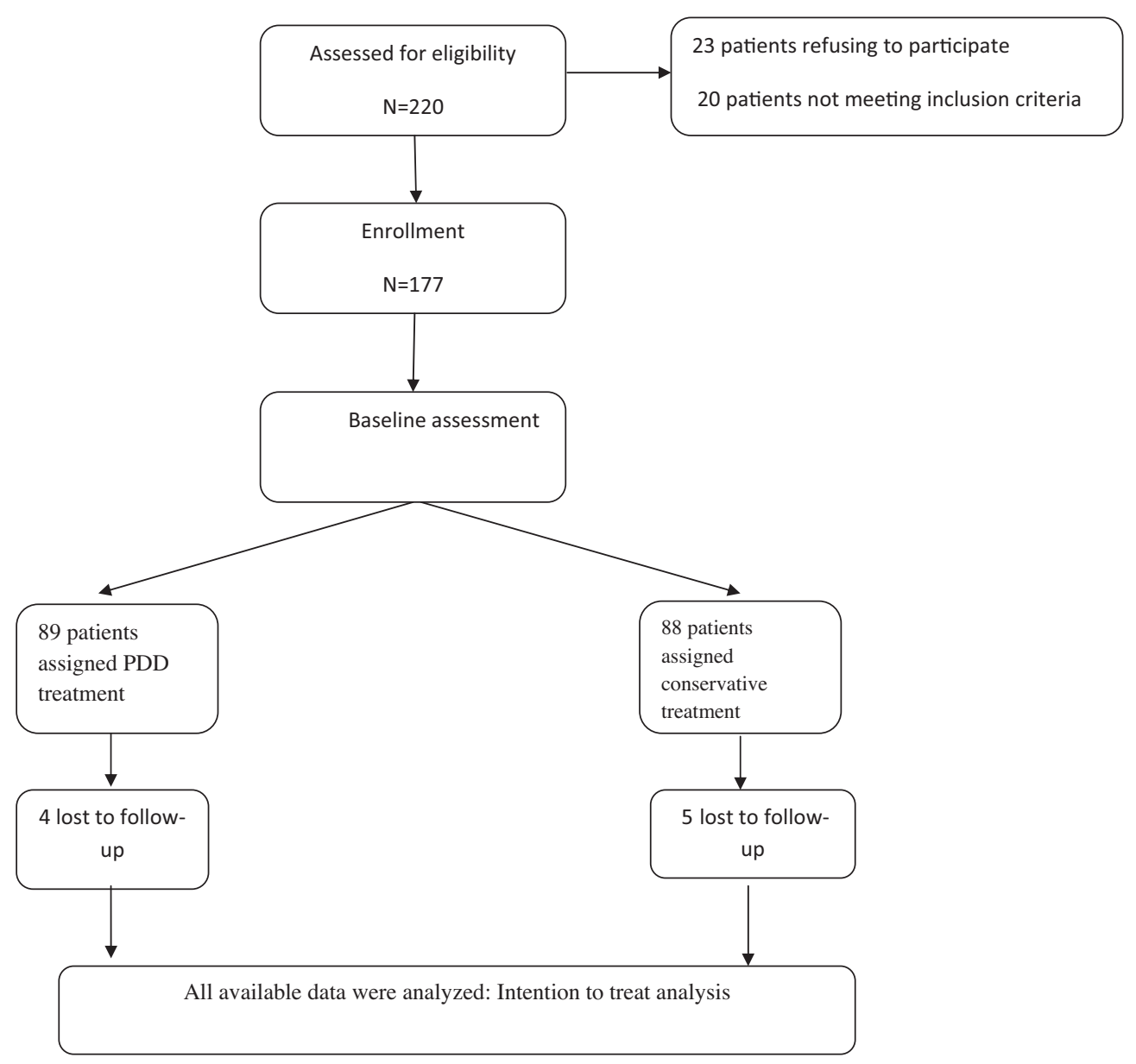

Fig. 1 - Flowchart of patient recruitment and dropout. 


\subsection{Statistical analysis}

Normality of distribution for every dependent variable was assessed with the Kolmogorov-Smirnov test and through visual inspection of the data. An independent $t$ test and chi square were used to compare patients' characteristics.

A 2-way repeated-measures analysis of covariance (ANCOVA), with group (conservative, PDD) as the betweensubjects variable, time (baseline, 1 month, 3 months and 12 months) as the within-subjects variable, and age, sex, BMI and duration of radicular pain as covariate, was used to examine the effects of the intervention. Between-group effect size was calculated using Partial Eta squared. Post hoc analyses, with Bonferroni corrections, were applied in all comparisons. An intention-to-treat analysis was performed in comparing patient groups.

All statistical analyses were performed by an independent biostatistician with SPSS for Windows version 16.0. Results were considered statistically significant if the $p$-value was equal to or less than .05 for continuous variables. For percentage outcomes and non-parametric values, 95\% confidence intervals were used to show statistical significance.

\section{Results}

This study included 177 subjects: 89 in the percutaneous disc decompression (PDD) group and 88 in the conservative care (CC) group. After 12 months, nine patients $(5.1 \%$ of the overall patients studied) dropped out of the study, four in the PDD group and five in the conservative group (Fig. 1). Most participants in this study were female. All patients ranged from 20 to 70 years of age. Clinical and sociodemographic variables were comparable in both groups (Table 1). At

\begin{tabular}{|c|c|c|c|}
\hline Characteristic & $\begin{array}{c}\text { Conservative } \\
\text { treatment } \\
N=88\end{array}$ & $\begin{array}{c}\text { PDD } \\
N=89\end{array}$ & $P$ value \\
\hline & Mean, SD & & \\
\hline Age-years & $38.02(8.99)$ & $37.57(7.26)$ & 0.73 \\
\hline \multicolumn{4}{|l|}{ Employment status } \\
\hline Full time or part time & $34(38.6 \%)$ & 25 (28.1\%) & \\
\hline Housekeeper & $20(22.7 \%)$ & $27(30.3 \%)$ & \\
\hline Unemployed & $34(38.6 \%)$ & 37 (41.6\%) & 0.28 \\
\hline \multicolumn{4}{|l|}{ Sex } \\
\hline Male & 43 (48.9\%) & 36 (40.4\%) & \\
\hline Female & 45 (51.1\%) & $53(59.6 \%)$ & 0.16 \\
\hline \multicolumn{4}{|l|}{ Current smoking status } \\
\hline Yes & $56(63.6 \%)$ & $54(60.7 \%)$ & \\
\hline No & 32 (36.4\%) & 35 (39.3\%) & 0.40 \\
\hline Mean BMI $\mathrm{Kg} / \mathrm{m}^{2}$ & $25.40(4.15)$ & $26.12(4.53)$ & 0.77 \\
\hline $\begin{array}{l}\text { Duration of radicular } \\
\text { pain (months) }\end{array}$ & $25.91(8.63)$ & 18.64 (12.04) & 0.46 \\
\hline Herniation level & & & 0.602 \\
\hline L2-L3 & $3(3.4 \%)$ & $6(6.7 \%)$ & \\
\hline L3-L4 & $19(21.6 \%)$ & 15 (16.9\%) & \\
\hline L4-L5 & $21(23.9 \%)$ & $25(28.1 \%)$ & \\
\hline L5-S1 & 45 (51.1\%) & 43 (48.3\%) & \\
\hline
\end{tabular}

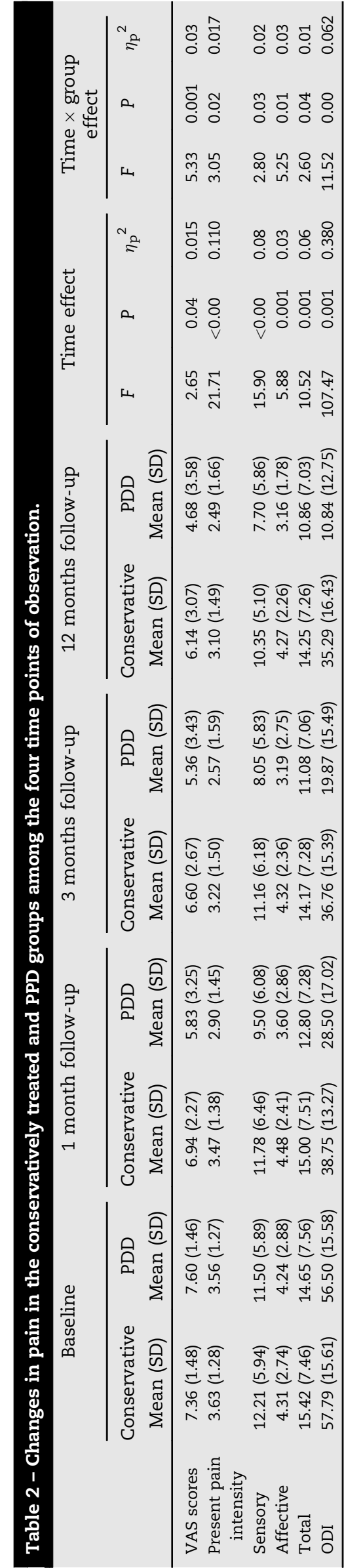


Table 3 - Covariates associated with the pain and disability across time.

\begin{tabular}{|c|c|c|c|c|c|c|c|c|c|c|c|c|}
\hline & \multicolumn{3}{|c|}{ Age } & \multicolumn{3}{|c|}{$\begin{array}{c}\text { Gender } \\
\text { (male vs. female) }\end{array}$} & \multicolumn{3}{|c|}{ BMI } & \multicolumn{3}{|c|}{$\begin{array}{c}\text { Pain duration } \\
\text { (sub-acute vs. chronic) }\end{array}$} \\
\hline & $F$ & $P$ & $\eta_{\mathrm{p}}^{2}$ & $F$ & $P$ & $\eta_{\mathrm{p}}{ }^{2}$ & $F$ & $P$ & $\eta_{\mathrm{p}}^{2}$ & $F$ & $P$ & $\eta_{\mathrm{p}}^{2}$ \\
\hline VAS scores & 4.37 & 0.005 & 0.073 & 4.58 & 0.03 & 0.02 & 9.23 & 0.001 & 0.03 & 3.32 & 0.02 & 0.02 \\
\hline Present pain intensity & 4.82 & 0.005 & 0.025 & 3.83 & 0.008 & 0.02 & 4.21 & 0.03 & 0.024 & 4.41 & 0.004 & 0.03 \\
\hline Sensory & 13.13 & 0.001 & 0.07 & 2.29 & 0.03 & 0.02 & 3.57 & 0.01 & 0.02 & 1.39 & 0.24 & 0.008 \\
\hline Affective & 5.79 & 0.001 & 0.04 & 5.90 & 0.001 & 0.03 & 2.59 & 0.04 & 0.02 & 4.32 & 0.013 & 0.025 \\
\hline Total & 9.94 & 0.001 & 0.06 & 3.85 & 0.01 & 0.02 & 4.33 & 0.04 & 0.025 & 13.83 & 0.001 & 0.08 \\
\hline ODI & 2.73 & 0.04 & 0.016 & 11.01 & 0.001 & 0.063 & 2.89 & 0.035 & 0.02 & 4.63 & 0.033 & 0.027 \\
\hline
\end{tabular}

Table 4 - Covariates associated with the quality of life across time.

\begin{tabular}{|c|c|c|c|c|c|c|c|c|c|c|c|c|}
\hline & \multicolumn{3}{|c|}{ Age } & \multicolumn{3}{|c|}{$\begin{array}{c}\text { Gender } \\
\text { (male vs. female) }\end{array}$} & \multicolumn{3}{|c|}{ BMI } & \multicolumn{3}{|c|}{$\begin{array}{c}\text { Pain duration } \\
\text { (sub-acute vs. chronic) }\end{array}$} \\
\hline & $F$ & $P$ & $\eta_{\mathrm{p}}{ }^{2}$ & $F$ & $P$ & $\eta_{\mathrm{p}}{ }^{2}$ & $F$ & $P$ & $\eta_{\mathrm{p}}{ }^{2}$ & $F$ & $P$ & $\eta_{\mathrm{p}}{ }^{2}$ \\
\hline PF & 2.76 & 0.04 & 0.016 & 2.47 & 0.02 & 0.02 & 0.861 & 0.035 & 0.005 & 3.09 & 0.02 & 0.018 \\
\hline $\mathrm{RP}$ & 1.47 & 0.22 & 0.009 & 0.72 & 0.53 & 0.004 & 0.255 & 0.858 & 0.001 & 0.451 & 0.71 & 0.003 \\
\hline BP & 2.59 & 0.04 & 0.020 & 0.219 & 0.88 & 0.001 & 0.26 & 0.61 & 0.002 & 3.60 & 0.01 & 0.021 \\
\hline GH & 0.59 & 0.44 & 0.003 & 3.08 & 0.02 & 0.018 & 0.582 & 0.62 & 0.003 & 1.66 & 0.173 & 0.010 \\
\hline VT & 2.69 & 0.04 & 0.016 & 0.28 & 0.83 & 0.002 & 0.73 & 0.53 & 0.004 & 0.24 & 0.86 & 0.001 \\
\hline SF & 0.50 & 0.68 & 0.003 & 0.68 & 0.56 & 0.004 & 0.74 & 0.52 & 0.004 & 0.59 & 0.62 & 0.003 \\
\hline $\mathrm{RE}$ & 1.263 & 0.286 & 0.007 & 0.972 & 0.40 & 0.006 & 0.436 & 0.73 & 0.003 & 2.610 & 0.04 & 0.015 \\
\hline $\mathrm{MH}$ & 0.183 & 0.90 & 0.001 & 0.252 & 0.86 & 0.001 & 0.43 & 0.72 & 0.003 & 5.31 & 0.001 & 0.030 \\
\hline PCS & 5.13 & 0.001 & 0.030 & 0.437 & 0.72 & 0.003 & 0.252 & 0.860 & 0.001 & 5.26 & 0.001 & 0.030 \\
\hline MCS & 0.872 & 0.455 & 0.005 & 1.42 & 0.23 & 0.008 & 0.708 & 0.54 & 0.004 & 3.351 & 0.019 & 0.02 \\
\hline
\end{tabular}

baseline, no significant differences were observed in clinical and sociodemographic variables between the two groups.

An ANCOVA was conducted to examine mean-level group differences in VAS across times. The results indicated that the VAS was reduced significantly across times in both groups $(p<0.05)$. Furthermore, there was a significant difference in VAS between the two groups as patients who received PDD treatment reported lower VAS score than those undergoing conservative treatment $(p<0.001)$. Distinct reductions in pain intensity, sensory, affective and total pain all were observed for patients who received PDD treatment (Table 2).

Concerning disability, as assessed by the ODI, repeated measure ANCOVA revealed a significant time $\times$ group interaction for ODI $[F(1,171)=11.52, p<0.05]$. Bonferroni post hoc analysis revealed that patients in the PDD group report significantly lower disability than those undergoing conservative treatment.

Looking for the ideal patient selection for the PDD procedure, better results were found in younger patients and those with a short period of radicular pain. Furthermore, being of male gender and lower BMI were also associated with better outcomes including VAS, quality of life and ODI (Tables 3 and 4). In addition to this, patients with sub-acute (i.e. 6 weeks to 3 months) pain reported better outcomes compared to those with pain of chronic duration (Tables 3 and 4).

Differences in health-related quality of life were observed during follow-up between the two groups (Table 5). Physically based subscales of the SF-36 reduced significantly in both groups across times (Table 5). However, no significant reduced change was seen for mental based subscales of the SF-36 for either group across times. PCS rose from baseline to 12 months in subjects who received PDD (Group $\times$ time interaction: $F=3.36, p=.01$ ).

There were no major complications related to the PDD procedure. Specifically, there were no cases of infection or nerve root injury. No significant clinical adverse events were observed in this study with the exception of minor local anesthetic-related side effects.

\section{Discussion}

In this study we directly compare nucleoplasty, a percutaneous PDD technique, to conservative treatment for patients with symptomatic lumbar disc herniations. The PDD procedure as well as conservative treatment both gave clinically useful effects on the primary outcome of VAS and disability. Findings from the secondary analyses support the primary analyses, showing significant positive effects on healthrelated quality of life especially in physically based SF-36 subscales but not for mental based subscales of the SF-36 at 1, 3 or 12 months. However, the PDD group had significantly a greater reduction of pain scores as well as better SF-36 and ODI results than the conservative group [9]. We found especially young patients and patients with a short period of radicular pain experienced better post-interventional results [19]. Other studies could also show better results in patients with a short duration of symptoms but they could not find the gender, BMI and age effect [20].

So far to date several observational studies of limited to fair quality have shown that the PDD procedure is a possibly effective treatment in managing radicular pain for patients 


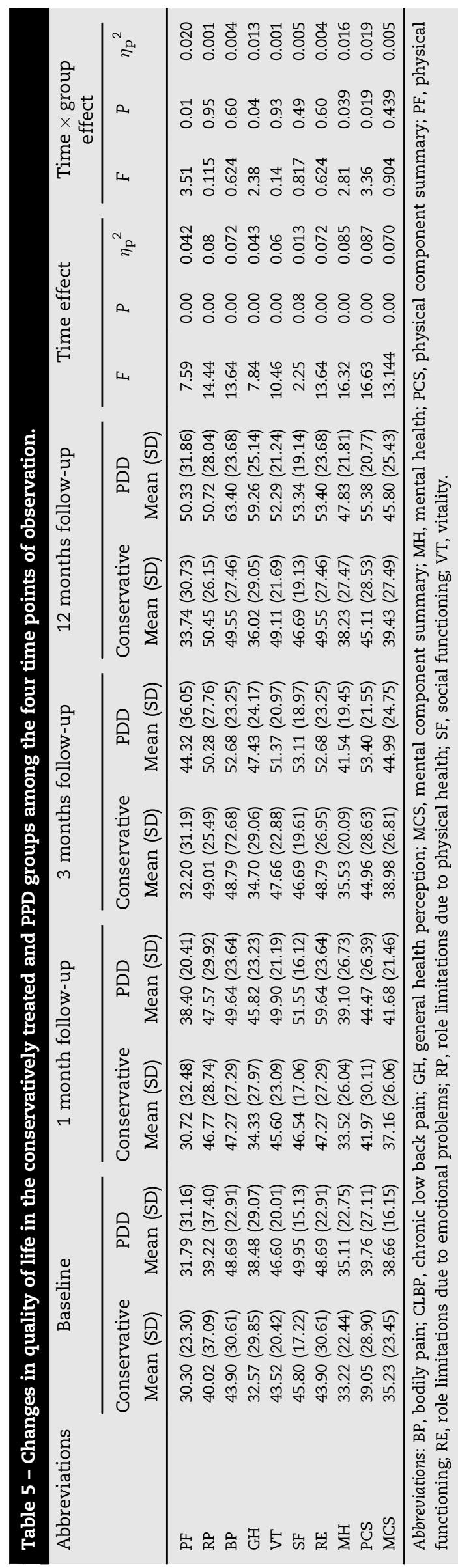

with ipsilateral contained disc herniation who are refractory to conservative therapy [9-11,21]. To the best of our knowledge, this is the first randomized controlled trail looking for PDD versus conservative treatment in patients complaining of primarily leg pain $[11,22]$. Conservative treatment was chosen to be the control group, as this is the first treatment option in patients with refractory sciatica with or without back pain. So we compared the PDD procedure results with a group who received optimal care [22,23]. While all patients were randomized to treatment groups due to the nature of the different interventions in both groups it was not possible to blind participants and healthcare providers from knowledge of which intervention a participant received. Although the lack of blinding might be considered as a weakness in the study design, we tried to reduce this risk of bias, as all patients were treated according to a strict protocol.

Furthermore the outcome assessors were blinded from knowledge of which intervention a participant received. Inclusion criteria specified that all participants had to have a failed conservative treatment, which may had the possibility to bias the study in favor of PDD method. Our results support the literature that PDD is a safe procedure [11,24], as the complication rate for lumbar nucleoplasty was $1.8 \%$ [9].

As the inclusion criteria for all patients in the nucleoplasty group was to have failed conservative treatment, this could have led to a bias against the PDD group, as those patients experienced a significantly longer duration pain symptoms. Furthermore, the PDD group has a higher VAS score and pain intensity at baseline.

Gerszten et al. could show in a randomized controlled clinical trail the superiority of PDD intervention over transformational epidural steroid injection in patients with an initial failed treatment of epidural steroid injections [13]. In our study functional capacity, measured via ODI, increased according to baseline and in comparison to conservative treatment. This is similar to the results of other studies [13,24]. Different studies have shown that conservative treatment, including epidural steroid injection, is known not to have a pain reducing long-term effect [25]. This might explain why Eichen et al. could not find a conservative pain reduction effect in compression alone compared to baseline [9]. The VAS/NPS reduction for lumbar nucleoplasty was demonstrated to be superior to conservative therapy within the first 3 months [9]. The results of this investigation also show a significant VAS superiority at 12 months.

\section{Conclusion}

Lumbar PDD is a minimally invasive safe procedure, being able to increase functional mobility and reduce leg pain in a long term follow-up in patients with symptomatic contained lumbar disc herniations. It appears to be most effective for younger patients with relatively short duration of pain symptoms.

\section{Conflict of interest}

None declared. 


\section{Acknowledgement and financial support}

The study was funded by Qazvin University of Medical Sciences. The sponsor of this study had no role in study design, data collection, data analysis, data interpretation, or writing of the report. All authors had full access to the data in the study and the corresponding author had final responsibility to submit for publication.

\section{Ethics}

The work described in this article has been carried out in accordance with The Code of Ethics of the World Medical Association (Declaration of Helsinki) for experiments involving humans; Uniform Requirements for manuscripts submitted to Biomedical journals.

\section{R E F E R E N C E S}

[1] Picavet HS, Hazes JM. Prevalence of self reported musculoskeletal diseases is high. Ann Rheum Dis 2003;62:644-50.

[2] Hestbaek L, Leboeuf-Yde C, Manniche C. Low back pain: what is the long-term course? A review of studies of general patient populations. Eur Spine J 2003;12:149-65.

[3] Andersson GB, Brown MD, Dvorak J, Herzog RJ, Kambin P, Malter A, et al. Consensus summary of the diagnosis and treatment of lumbar disc herniation. Spine (Phila Pa 1976) 1996;21:75S-8S.

[4] Kelsey JL, White 3rd AA. Epidemiology and impact of lowback pain. Spine (Phila Pa 1976) 1980;5:133-42.

[5] Praemer A, Furner S, Rice DP. Musculoskeletal conditions in the United States. Rosemont, IL: American Academy of Orthopaedic Surgeons; 1999.

[6] Manchikanti L, Falco FJ, Pampati V, Cash KA, Benyamin RM, Hirsch JA. Cost utility analysis of caudal epidural injections in the treatment of lumbar disc herniation, axial or discogenic low back pain, central spinal stenosis, and post lumbar surgery syndrome. Pain Phys 2013;16:E129-43.

[7] Peul WC, van Houwelingen HC, van den Hout WB, Brand R, Eekhof JA, Tans JT, et al., Leiden-The Hague Spine Intervention Prognostic Study G. Surgery versus prolonged conservative treatment for sciatica. N Engl J Med 2007;356:2245-56.

[8] Welch WC, Gerszten PC. Alternative strategies for lumbar discectomy: intradiscal electrothermy and nucleoplasty. Neurosurg Focus 2002;13:E7.

[9] Eichen PM, Achilles N, Konig V, Mosges R, Hellmich M, Himpe B, et al. Nucleoplasty, a minimally invasive procedure for disc decompression: a systematic review and meta-analysis of published clinical studies. Pain Phys 2014;17:E149-73.

[10] Manchikanti L, Falco FJ, Benyamin RM, Caraway DL, Deer TR, Singh V, et al. An update of the systematic assessment of mechanical lumbar disc decompression with nucleoplasty. Pain Phys 2013;16:SE25-54.

[11] Gerges FJ, Lipsitz SR, Nedeljkovic SS. A systematic review on the effectiveness of the nucleoplasty procedure for discogenic pain. Pain Phys 2010;13:117-32.

[12] Manchikanti L, Derby R, Benyamin RM, Helm S, Hirsch JA. A systematic review of mechanical lumbar disc decompression with nucleoplasty. Pain Phys 2009;12: 561-72.

[13] Gerszten PC, Smuck M, Rathmell JP, Simopoulos TT, Bhagia $\mathrm{SM}$, Mocek CK, et al. Plasma disc decompression compared with fluoroscopy-guided transforaminal epidural steroid injections for symptomatic contained lumbar disc herniation: a prospective, randomized, controlled trial. J Neurosurg Spine 2010;12:357-71.

[14] Gibson JN, Waddell G. Surgical interventions for lumbar disc prolapse. Cochrane Database Syst Rev 2007;CD001350.

[15] Sathyakumar V, Radaideh M. Standardizing nomenclature and classification of lumbar disc pathology among spine practitioners. Am J Roentgenol 2012;198.

[16] Mousavi SJ, Parnianpour M, Mehdian H, Montazeri A, Mobini B. The Oswestry Disability Index, the Roland-Morris Disability Questionnaire, and the Quebec Back Pain Disability Scale: translation and validation studies of the Iranian versions. Spine (Phila Pa 1976) 2006;31:E454-9.

[17] Pakpour AH, Saffari M, Yekaninejad MS, Panahi D, Harrison AP, Molsted S. Health-related quality of life in a sample of Iranian patients on hemodialysis. Iran J Kidney Dis 2010;4:50-9.

[18] Adelmanesh F, Arvantaj A, Rashki H, Ketabchi S, Montazeri A, Raissi G. Results from the translation and adaptation of the Iranian Short-Form McGill Pain Questionnaire (I-SF-MPQ): preliminary evidence of its reliability, construct validity and sensitivity in an Iranian pain population. Sports Med Arthrosc Rehabil Ther Technol 2011;3:27.

[19] Lemcke J, Al-Zain F, Mutze S, Meier U. Minimally invasive spinal surgery using nucleoplasty and the Dekompressor tool: a comparison of two methods in a one year follow-up. Minim Invasive Neurosurg 2010;53:236-42.

[20] Karaman H, Tufek A, Olmez Kavak G, Yildirim ZB, Temel V, Celik F, et al. Effectiveness of nucleoplasty applied for chronic radicular pain. Med Sci Monit 2011;17:CR461-6.

[21] Konig V, Eichen PM, Achilles N, Mosges R. A systematic review of RCTs with nucleoplasty - an update. Pain Phys 2013;16:E45-6.

[22] Bhagia SM, Slipman CW, Nirschl M, Isaac Z, El-Abd O, Sharps LS, et al. Side effects and complications after percutaneous disc decompression using coblation technology. Am J Phys Med Rehabil 2006;85:6-13.

[23] Smuck M, Benny B, Han A, Levin J. Epidural fibrosis following percutaneous disc decompression with coblation technology. Pain Phys 2007;10:691-6.

[24] Bokov A, Skorodumov A, Isrelov A, Stupak Y, Kukarin A. Differential treatment of nerve root compression pain caused by lumbar disc herniation applying nucleoplasty. Pain Phys 2010;13:469-80.

[25] Pinto RZ, Maher CG, Ferreira ML, Hancock M, Oliveira VC, McLachlan AJ, et al. Epidural corticosteroid injections in the management of sciatica: a systematic review and metaanalysis. Ann Intern Med 2012;157:865-77. 